\title{
EL ABASTECIMIENTO DE AGUA EN LOS ESPACIOS Y DESTINOS TURÍSTICOS DE ALICANTE Y MURCIA
}

\author{
Carlos J. Baños Castiñeira, J. Fernando Vera Rebollo y Daniel Díez Santo \\ Instituto Universitario de Investigaciones Turísticas \\ Universidad de Alicante ${ }^{1}$
}

\section{RESUMEN}

A partir del análisis de modelos locales, este artículo presenta las relaciones entre recursos de agua y actividad turística en la Región de Murcia y en el área meridional de la provincia de Alicante. En su conjunto, se trata del territorio abastecido por la Mancomunidad de los Canales del Taibilla, sistema público que cuenta con una larga trayectoria y cuyo papel resulta esencial para entender las magnitudes de la oferta y demanda turística, en el momento actual, y la dinámica territorial de este espacio. La importancia del turismo en la economía y las tendencias que se perfilan para esta actividad, hacen aconsejable realizar aproximaciones a las tipologías de gasto del agua a la hora de establecer estrategias de futuro sobre la gestión de los recursos.

Palabras clave: turismo, gasto de agua, tipologías locales de consumo, Mancomunidad de los Canales del Taibilla.

\section{ABSTRACT}

Starting from the analysis of local models, this article presents the relationship between the water resources and the tourist activity in the region of Murcia and the southern area of the province of Alicante. In its entirety, it is the territory supplied by the Mancomunidad (an association of municipalities) de los Canales del Taibilla, a public system with a long course of development and whose role it is essential to understand the extent of the tourist supply and demand at the present time and the territorial dynamics of this area. The relevance of tourism in the economics and the trends that are taking shape in this activity, seem to recommend an approach to the typologies of water consumption in order to provide future strategies for the management of resources.

Key words: tourism, water consumption, local typologies of consumption, Mancomunidad (association of municipalities) de los Canales del Taibilla.

1 El presente artículo se enmarca en el proyecto de investigación CSO-00613 MICINN, Plan Nacional de I+D+I, sobre Renovación de los destinos turísticos consolidados del litoral, que se lleva a cabo en el Instituto Universitario de Investigaciones Turísticas de la UA. 


\section{Introducción}

La actividad turística presenta vínculos y relaciones directas con el abastecimiento de agua, dado que éste actúa sobre los destinos en sus facetas de factor condicionante y recurso del que depende la implantación y el desarrollo de la actividad (Rico, 2007; Vera y Torres, 1999; Vera, 2006). Algo que resulta especialmente notorio en ámbitos como el del presente estudio, cuyas condiciones climáticas vienen marcadas por la irregularidad y la consiguiente escasez en los recursos de agua disponibles (Gil Olcina y Rico, 2007; Morales Gil, 2001; Olcina Cantos, 2002).

- La disponibilidad de agua ha actuado como factor condicionante de los procesos de funcionalización turística del territorio, favoreciendo el despegue y la configuración de las áreas de destino turístico. Hasta tal punto es así que, ante la parquedad de los recursos en la franja costera, se observan correspondencias lineales entre la fecha de la integración de los municipios en el organismo indicado, con la consiguiente garantía de abastecimiento, y el crecimiento fulgurante de sus licencias de construcción y del espacio urbanizado. Es el caso de Torrevieja, que se incorpora a la Mancomunidad de los Canales del Taibilla desde 1972/73, y cuyo crecimiento ha sido espectacular (Vera \& Ivars, 2003). Pero en general son todas las poblaciones afectadas las que se han apoyado en este factor para su desarrollo turístico-residencial, incluida la propia capital alicantina.

- El abastecimiento a las áreas turísticas, como parte del suministro a poblaciones, es casi determinante en la orientación del producto turístico de este espacio regional, centrado de forma básica en la modalidad de sol y playa, pero en su faceta de alojamiento en asentamientos residenciales surgidos ex novo, o en forma de viviendas vacacionales situadas en los propios núcleos urbanos.

- El agua es un fundamento de las nuevas orientaciones del modelo turístico, surgidas ante las motivaciones del turista-consumidor, que justifican la creación de productos como el golf, principal reclamo de las nuevas promociones de viviendas vacacionales en este espacio regional. De hecho, en el caso de Murcia y del sur de Alicante, la promoción incorpora los resort-golf como la imagen turística más diferenciada.

En este contexto, el organismo que constituye la Mancomunidad de los Canales del Taibilla (en adelante MCT), creado inicialmente como sistema de abastecimiento público de aguas para Cartagena y su base naval, se va configurando desde finales de los años cincuenta del pasado siglo mediante la incorporación a esta entidad, de forma progresiva y en distintos momentos, de todos los municipios de la Región de Murcia, a excepción de Jumilla y Yecla, un total de 43 entidades locales (Morales y Vera, 1987). Además del área murciana, forman parte de dicho sistema los municipios del área comprendida entre Alicante y su límite surprovincial, otros 34 entes locales, entre los que se incluyen las tres mayores ciudades de esta provincia en cuanto a número de habitantes (Alicante, Elx y Torrevieja), además de numerosas poblaciones que superan los 20.000 habitantes y que, en su conjunto, configuran el área abastecida por la MCT al sur de la Comunidad Valenciana. Por tanto un área que excede la propia delimitación de la Confederación Hidrográfica del Segura e incorpora entidades pertenecientes a la del Júcar. Un espacio que integra destinos turísticos emblemáticos, tanto por sus magnitudes de oferta y demanda como por su imagen y proyección en el mercado nacional y en el exterior. 
La garantía de dicho abastecimiento ha tenido una pieza clave en las aguas del trasvase Tajo-Segura que llegan a este territorio a partir del año 1979 y que, desde entonces, suponen un aporte básico, en torno al 50\%, del conjunto de caudales suministrados por este organismo de distribución de agua en alta a los diferentes municipios integrados ${ }^{2}$.

\section{Breve caracterización del modelo turístico regional}

El área de abastecimiento de la MCT no coincide con un único espacio regional, por lo que, a efectos estadísticos, es necesario diferenciar entre la Región de Murcia y la parte de la provincia de Alicante integrada en este organismo.

En su conjunto, la principal atracción turística de este ámbito, como en el resto del litoral mediterráneo, ha sido y sigue siendo el clima y las playas, por lo que el mayor peso del sistema turístico radica en los municipios costeros y en su prolongación hacia el ámbito prelitoral. En mayor o menor grado, los municipios comparten un rasgo esencial definitorio de su modelo turístico como es el predomino abrumador de la oferta residencial, es decir la que se relaciona con el uso de viviendas no principales o de utilización vacacional. Basta indicar que el índice de función residencial no permanente, resultado de la relación de proporcionalidad entre el total de viviendas y la población censada, cuyo valor viene a situarse en torno a 0,5 en ciudades convencionales, alcanza en los municipios turísticos de este área valores superiores a 1 (los más elevados son 1,46 en Los Alcázares, Murcia, y 1,26, en Torrevieja, Alicante) (Vera, 2005). Si bien un notable contingente de la vertiente del alojamiento residencial se comercializa para el uso permanente de ciudadanos procedentes de otros países que tienden, cada vez más, a empadronarse en los lugares donde adquieren su residencia. En su conjunto, se trata de municipios considerados turísticos, pero cuya característica más acentuada, dentro de esta función económico-territorial, es la promoción y venta o alquiler de unidades residenciales.

En el caso murciano, su estructura productiva ha sufrido notables transformaciones en las últimas décadas, incrementándose la importancia del sector servicios. Así, según la Contabilidad Regional de España elaborada por el Instituto Nacional de Estadística (INE), mientras los servicios representaban en 1990 el 61,71\% del Valor Añadido Bruto (VAB), en 2008 su participación era del $67,22 \%$, descendiendo la agricultura hasta el $5,01 \%{ }^{3}$. Paralelamente, en las cifras de empleo también se constata una pérdida de

2 El volumen de agua aportado por el trasvase Tajo-Segura para el abastecimiento de los municipios incorporados a la Mancomunidad de los Canales del Taibilla ha sido clave para entender el aumento poblacional y del parque de viviendas experimentados en la Región de Murcia y en una parte sustancial de la provincia de Alicante, durante los últimos veinte años. No obstante, el sistema ha comenzado a mostrar debilidades que ha sido necesario solucionar con los nuevos mecanismos ofrecidos por la legislación (mercados del agua) o las nuevas tecnologías (desalación). Para la planificación de las dotaciones necesarias a corto y medio plazo, la Mancomunidad de los Canales del Taibilla no puede depender de la aleatoriedad de los recursos del río Taibilla —en franca disminución en la última década - o de las aportaciones que se produzcan a través del canal del trasvase, que están siendo menores también en los últimos años. De ahí que la incorporación de caudales procedentes de la desalación, con la puesta en marcha de las desaladoras incluidas en el programa AGUA, en territorio de la Mancomunidad, son una realidad necesaria para garantizar el incremento de los consumos que se producirá en los próximos años.

De este modo, la cantidad de agua del Trasvase Tajo-Segura que se incorpora a la dotación anual de la MCT presenta una tendencia decreciente desde 2000, en cifras absolutas y relativas. En 2007 supuso $114 \mathrm{hm}^{3}$ (el 50\% del total de los recursos utilizados por la Mancomunidad) frente a los $131 \mathrm{hm}^{3}$ del año 2000 (66\% de los recursos totales de la Mancomunidad). En contra, el volumen de agua de las aportaciones extraordinarias y sobre todo de la desalación ha sufrido un incremento constante en este mismo intervalo (11\% en 2000 frente a $32 \%$ en 2007).

3 Datos obtenidos de la estimación avance del INE 2008 (precios de mercado o precios corrientes). 
relevancia de la agricultura, ganadería y pesca, actividades que han pasado de representar el 13,32\% del empleo en 1990 a un 7,21\% en 2008. Por su parte, los servicios concentran el $64,10 \%$ del empleo total, confirmándose como un sector trascendental para la economía regional. Dentro del sector servicios, destaca el crecimiento de la hostelería que en 2007 representaba el 5,49\% del VAB regional incluidos los efectos directos, indirectos e inducidos, aportando 29.800 empleos, el 4,87\% de la cifra de empleo estimada para Murcia.

En este contexto de terciarización, la Región de Murcia viene registrando un continuo crecimiento de la oferta de alojamiento turístico, tanto en número de establecimientos como en plazas. A finales de 2008 , se alcanzaba un total de 49.000 plazas ofertadas en establecimientos oficiales (García y García, 2009, p. 499) frente a las 38.000 que había en 1999. Si bien destaca el mayor dinamismo de la oferta hotelera, que suma 20.000 plazas, y el del alojamiento rural, con un importante incremento en los últimos años situándose en 3.183 plazas, el $11 \%$ del total regional. Un verdadero despegue de esta función en áreas de interior, con un nuevo modelo asociado a los valores del patrimonio natural, histórico y cultural, aunque este tipo de turismo no tiene, al menos por ahora, implicaciones relevantes en el gasto de agua.

Por lo que se refiere a la demanda turística, en 2008 el total de de viajeros alojados alcanza la cifra de 1.188.916 mientras que las pernoctaciones superan los 2’969 millones (Encuesta de Ocupación Hotelera, INE), un crecimiento notable respecto a años precedentes, a pesar de la tendencia general a la reducción del tiempo de estancia media.

Esta demanda se compone mayoritariamente de turistas de procedencia nacional, el $82 \%$, mientras que el turismo extranjero alcanza el 17\%. Dentro del turismo nacional destacan como principales mercados emisores la Comunidad de Madrid, con un 20\%, cifra similar a la que aporta el turismo interno de la propia Región de Murcia. Otro 18\% lo aporta la Comunidad Valenciana, especialmente dirigido al interior rural.

En relación a la distribución geográfica de la oferta turística, la política turística regional promociona la totalidad de su territorio como destino turístico, si bien es evidente la diversidad de entornos y de niveles de especialización en la prestación de servicios turísticos. Por entornos territoriales de la Región, la capital murciana y La Manga concentraban más del 55\% del movimiento de viajeros en 2000, mientras que en 2008 esta polarización ha descendido a un $45 \%$ por el efecto de la creación y configuración de otros destinos y productos. Como ejemplo de esta diversificación funcional y espacial del turismo, es notable el efecto del incremento de hoteles en municipios del Mar Menor, la eclosión turística del litoral suroccidental (Águilas y Mazarrón), el despegue de los nuevos espacios receptores de turismo urbano (Cartagena y Lorca) y el de los destinos del interior (comarca del Noroeste especialmente). De igual modo, en cuanto a datos de pernoctaciones, la Manga dominaba el panorama turístico regional en 2000 (casi el 40\% del total), pero en 2008 su captación se reduce al $28 \%$ por el efecto de los nuevos destinos que aparecen en el territorio regional, sin olvidar dos puntos de destino relacionados con la tradición termal, en Archena y Fortuna

Pero el gran crecimiento del turismo en la Región de Murcia, hasta la crisis de 2009, responde esencialmente a la eclosión de un nuevo modelo que tiene en la promoción de conjuntos residenciales asociados al golf su más claro exponente, en forma de nuevos asentamientos que albergan miles de viviendas de uso vacacional y turístico, no incluidas en la oferta reglada (Vera, 2005). Es decir, se trata de un movimiento turístico no contabilizado en las magnitudes y fuentes convencionales del sector y cuya unidad de producción son las urbanizaciones turísticas, resort-golf, asociado a la dinámica inmobiliaria y como respuesta a la demanda internacional de viviendas en áreas que disfrutan 
de confort climático y que son accesibles a la clientela extranjera, merced a los enlaces que posibilitan las compañías aéreas de bajo coste implantadas en los aeropuertos del entorno (Vera \& Ivars, 2009).

En cuanto al área suralicantina es evidente el predominio de la vertiente residencial del modelo turístico, incluida la propia capital. El área abastecida por la MCT en Alicante representa algo más del $30 \%$ del espacio provincial y, en su conjunto, la oferta turística que concentra suma casi 32.000 plazas de alojamiento turístico reglado, repartidas desigualmente entre distintas modalidades de establecimientos (hoteles, hostales, campamentos de turismo, apartamentos, casas rurales y albergues), que equivalen al 19\% del total de la oferta turística de la provincia de Alicante. Una oferta distribuida también de forma desigual entre los municipios del área ya que es notable su polarización en el territorio, considerando que la parte más sustancial de la planta hotelera está concentrada en las dos mayores ciudades, con 32 establecimientos (62\%), 11 de ellos de cuatro estrellas, que suman más de 3.300 plazas. En su conjunto, este espacio representaba en 1991 el $54,67 \%$ del empleo total de la provincia de Alicante, mientras que en 2006 alcanzaba el $58 \%$. Es decir, incrementa su aportación económica, en términos absolutos, así como en su relación sobre el total.

En realidad, la dedicación al turismo, como en la vecina Región de Murcia, tiene una impronta asociada de manera rotunda al fenómeno residencial, con más trayectoria que en el caso anterior y no tan dependiente de los resort-golf, pero relacionada con la promoción de unidades residenciales. La irrupción de corrientes de afluencia de turistas hacia las áreas costeras, propulsan un profundo cambio cualitativo y cuantitativo en la forma de entender la función turística, donde el hecho más significativo es la transformación del modelo económico, territorial y social de estas poblaciones, a partir de su dedicación a la construcción de alojamiento (viviendas y apartamentos) en asentamientos y núcleos urbanos y el vuelco de las economías locales hacia la prestación de servicios, relacionados con la presencia del contingente de población estacional. Estos cambios han relegado a un papel muy secundario o casi residual a las actividades de base primaria (pesca, extracción salinera y agricultura), ante la nueva dinámica económica marcada por la eclosión del sector de la construcción y afines, que actuará como motor de las transformaciones, junto con el aparato de servicios: actividades inmobiliarias, comercio, transporte, hostelería, entre otras.

La forma en que se implanta esta dinámica en el modelo económico-territorial de cada ámbito local analizado presenta diferencias que derivan de contextos internos muy concretos. Influyen factores, en cada caso, como el papel de los agentes actuantes, públicos y privados, la estructura de la propiedad de la tierra y su repercusión en el planeamiento urbanístico a la hora de desarrollar promociones residenciales, las conocidas como urbanizaciones, el peso de otras actividades económicas como posible contrapunto al turismo o la ausencia o debilidad de éstas como factor propulsor de los cambios, hasta la misma presencia de agentes externos como protagonistas del nuevo modelo. También ha habido otros factores que contribuyeron a explicar las diferencias en la nueva configuración económica y territorial, como la propia base de recursos naturales (playas, esencialmente, en la primera etapa, y posteriormente la presencia de lomas y colinas con vistas al mar) con que contaban algunos municipios, y el modelo de asentamiento de la población, esencialmente la mayor o menor proximidad de la cabecera municipal a la ribera del mar.

En suma, los actuales destinos turísticos que integran este espacio, aunque con pautas y procesos comunes, no son homogéneos y responden a una caracterización y dinámicas turísticas diferenciadas, pero tienen en común la pertenencia a un gran sistema de abastecimiento público de aguas que garantiza el suministro a poblaciones. 


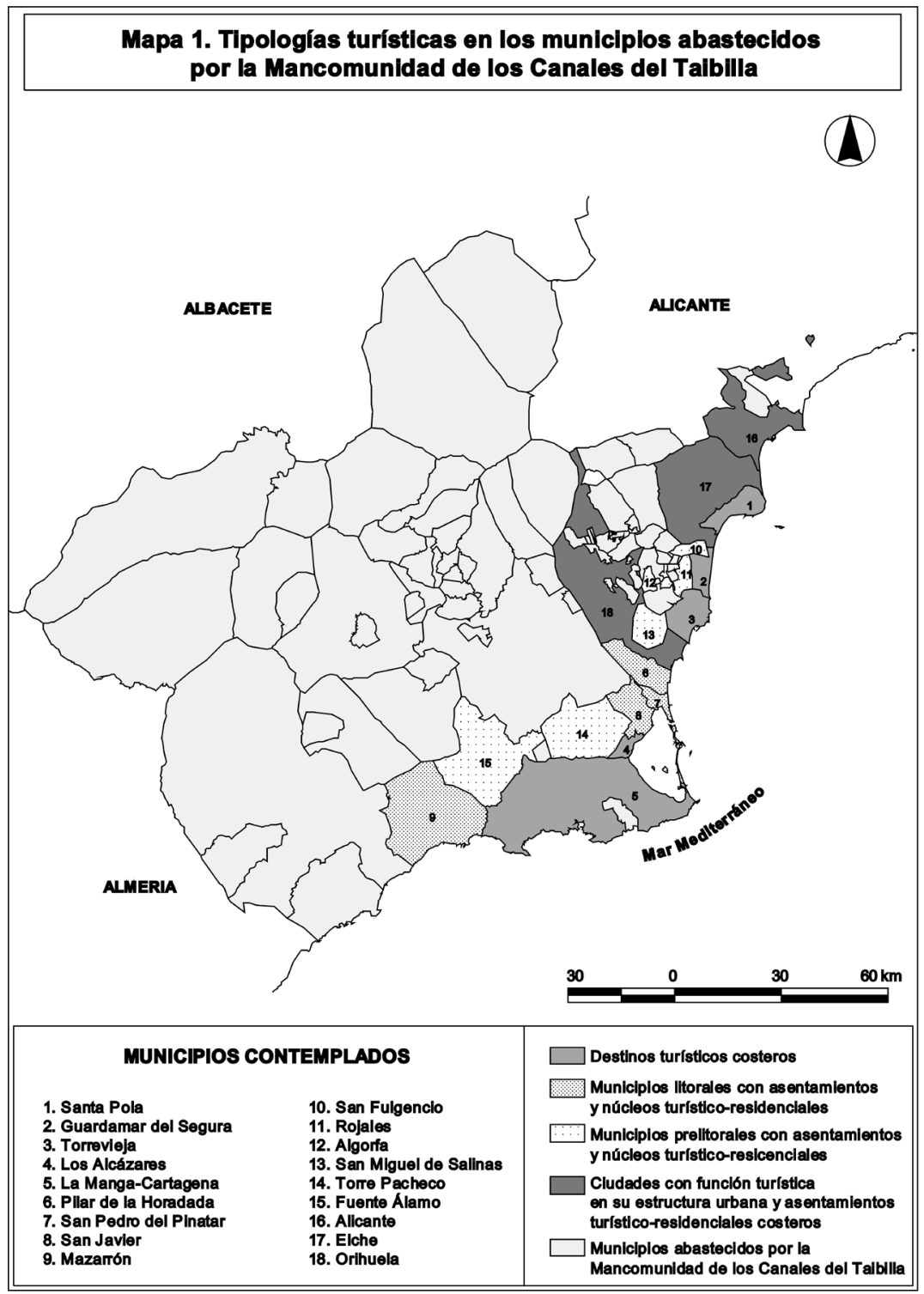

Elaboración propia a partir de datos de la Mancomunidad de los Canales del Taibilla.

\section{Tipología de destinos turísticos locales}

La consideración de varios indicadores (tipo de oferta turística, evolución demográfica, crecimiento de los presupuestos municipales) sobre la base de procesos comunes en cuanto a su transformación, pero considerando las diferencias en los modelos locales, permite establecer una tipología de destinos turístico-residenciales en el área abastecida 
por la Mancomunidad de los Canales del Taibilla en la Región de Murcia y en la provincia Alicante, espacio en el que la función turística tiene repercusiones considerables sobre las estructuras territoriales y económicas locales.

\subsection{Destinos turísticos costeros}

Torrevieja, Guardamar del Segura, Santa Pola, Los Alcázares y Águilas son municipios cuyo núcleo principal de población se ha transformado de modo más directo y rotundo con la irrupción de la actividad turística en su dinámica económica y con los procesos urbanísticos asociados, que afectan a todo su término municipal. El núcleo urbano se remodela y se ensancha al tiempo que se construyen nuevos asentamientos periféricos. La actividad económica gira en torno a la construcción y actividades afines a la vez que se ha desarrollado un complejo y extenso sistema de servicios de todo tipo: comerciales, hosteleros, de ocio, restauración, asesorías, transporte, informática, entre otros, donde también es destacable el hecho de que la administración municipal sea la mayor entidad en cuanto a volumen de empleo local. A este grupo de municipios se añade el conjunto conocido como La Manga del Mar Menor, destino turístico conformado por conjuntos urbano-turísticos que pertenecen administrativamente a dos municipios murcianos: Cartagena y San Javier. Sin embargo, su particularidad territorial, funcional y sectorial y su imagen como destino turístico, aconsejan su análisis, en los casos en que las limitaciones de orden estadístico lo permitan, como tal destino turístico, independientemente de la compartimentación administrativa municipal ${ }^{4}$.

La creación de espacio urbano-turístico ha potenciado intensas dinámicas inmobiliarias, de manera que, al tiempo que la construcción se convierte en la principal actividad económica, la vivienda de uso estacional, en sus diferentes formas y tipologías, es la modalidad de alojamiento turístico-vacacional casi hegemónica. El análisis cuantitativo del volumen esas plazas de alojamiento en viviendas secundarias, asociadas en su gran mayoría a un uso turístico residencial que se comercializan en circuitos alegales o constituyen segundas residencias, resulta harto complicado. Algunos indicadores permiten una aproximación a esa realidad siquiera en forma de estimación. El municipio de Torrevieja concentra más de 216.000 de estas plazas de alojamiento en vivienda de potencial uso turístico (VPUT), de manera que se configura en el destino vacacional de mayor capacidad de alojamiento de todo el área MCT. Los otros dos destinos alicantinos poseen en conjunto aproximadamente 100.000 plazas, 63.000 Santa Pola y 34.000 Guardamar del Segura $^{5}$. Los municipios murcianos presentan si cabe una mayor dificultad a la hora de establecer el volumen de ese alojamiento potencial, sin embargo el Censo de Población y Vivienda de 2001 pone de manifiesto el notable peso de la vivienda secundaria, alrededor de 24.000 viviendas en el sector de La Manga del Mar Menor de las que más de 23.000 son de uso secundario, más de 16.000 unidades residenciales de utilización no principal en Los Alcázares y cerca de 5.000 en Águilas, siendo este además el sexto municipio con mayor volumen de construcción de viviendas de la región para el periodo 2002-2007 con más de 4.500 finalizadas.

Frente a la abrumadora presencia de las plazas de alojamiento en vivienda, la oferta de plazas turísticas regladas es relativamente reducida, si bien se corresponde con el mayor

4 No obstante, como se pone de manifiesto en el trabajo, las dinámicas turísticas-residenciales en la Manga tampoco se corresponden de manera lineal con los denominados destinos turísticos costeros. Sus características funcionales, el tipo de oferta turística instalada, la tipología de la demanda o el comportamiento estacional de la misma reflejan una tipología única en el área de estudio.

5 Plan de Espacios Turísticos de la Comunidad Valenciana. 
volumen del área de estudio. De manera global esa oferta turística está integrada por algo más de 27.000 plazas en total, repartidas entre apartamentos, camping y hoteles de categoría media (Tabla 1) un tercio de las cuales se ubica en el sector de La Manga del Mar Menor. Desde el punto de vista cualitativo, destaca la presencia de establecimientos hoteleros de 4 estrellas, ocho en La Manga que suman 3.700 plazas, uno en Guardamar del Segura inaugurado en 1999, dos en Águilas y tres en Los Alcázares, éstos abiertos en los últimos años en relación con nuevas dinámicas turísticas. Las localidades de Torrevieja y Santa Pola mantienen todavía una oferta de alojamiento exigua y de tipo medio-bajo dado el sesgo eminentemente residencial con el que se ha construido el sistema de oferta y el escaso interés e incentivo con que han contado las empresas y cadenas hoteleras por este tipo de municipio.

Tabla 1

OFERTA DE ALOJAMIENTO REGLADA 2009 ( $N^{\circ}$ DE PLAZAS)

\begin{tabular}{|l|c|c|c|c|}
\hline & Hoteles & Hostales & Apartamentos & Campings \\
\hline Águilas & 827 & 158 & 431 & 1.149 \\
\hline Guardamar & 1.637 & - & 514 & 1.368 \\
\hline La Manga & 4.514 & - & 4.478 & - \\
\hline Los Alcázares & 967 & 99 & 1.489 & - \\
\hline Santa Pola & 825 & 113 & 2.666 & 1.257 \\
\hline Torrevieja & 1.228 & 71 & 2.101 & 1.298 \\
\hline TOTAL & 9.998 & 441 & 11.679 & 5.072 \\
\hline
\end{tabular}

Fuente: Conselleria de Turisme, Generalitat Valenciana. Consejería de Cultura y Turismo, Región de Murcia.

Tabla 2

EVOLUCIÓN DE LA POBLACIÓN Y LOS PRESUPUESTOS MUNICIPALES

\begin{tabular}{|l|c|c|}
\hline & Incremento población 2000-2009 \% & Incremento presupuestos 2001-2008 \% \\
\hline Águilas & 25,31 & 100,4 \\
\hline Guardamar & 75,1 & 65,9 \\
\hline Los Alcázares & 107,9 & 37,5 \\
\hline Santa Pola & 67,8 & 44,7 \\
\hline Torrevieja & 102,2 & 46,5 \\
\hline TOTAL & 76,2 & 52,7 \\
\hline
\end{tabular}

Fuente: INE, CIVIS, IVE, Caja España.

Las dinámicas económicas generadas por la actividad de la construcción han supuesto una profunda transformación de las estructuras demográficas de estas poblaciones litorales. Los cinco municipios, pues La Manga no ha producido tasas de empadronamiento considerables ${ }^{6}$, han pasado de 92.527 habitantes en 1996 a 200.033 en 2009, con una tasa de variación

6 En el caso de la Manga del Mar Menor en el año 2000 las entidades de población que conforman el destino contaban con 2.461 habitantes empadronados, cifra que asciende hasta 5.112 en 2009 . 
media de más de un $8 \%$ anual. Entre los destinos que conforman el grupo destaca, por su espectacularidad en el proceso, el caso de Torrevieja, convertida en la quinta entidad por su tamaño poblacional dentro de la Comunidad Valenciana y que prácticamente triplica su población durante ese periodo y que ha sobrepasado los 100.000 habitantes. Asimismo, los valores relativos son similares al caso de Los Alcázares. Por otra parte, en ambos municipios el porcentaje de población de origen extranjero, atraída por motivos de ocio o de mercado de trabajo, se sitúa próximo al 50\%. En el mismo sentido, los presupuestos municipales del conjunto de municipios se han visto incrementados en un 50\% entre 2001 y 2008. Resultan relevantes el disparo de Águilas que dobla su presupuesto municipal en apenas 8 años y el efecto de Torrevieja, que ronda los 100 millones de euros anuales de presupuesto (quinto puesto también entre los municipios de la Comunidad Valenciana), lo que se ha traducido en cuantiosas inversiones $\mathrm{y}$, a la vez, en un alto grado de endeudamiento municipal.

\subsection{Municipios litorales con asentamientos y núcleos turístico-residenciales}

San Pedro del Pinatar, Mazarrón, San Javier (excluido el sector de La Manga del Mar Menor) y El Pilar de la Horadada constituyen entidades locales donde la irrupción del turismo y residencialismo se produce sobre una estructura territorial en la que el núcleo principal, alejado de la costa, mantiene su dinámica propia, al tiempo que se configura un nuevo sistema de asentamientos en el frente costero.

El núcleo urbano contiguo a la fachada marítima se remodela y se ensancha al tiempo que se construyen nuevos asentamientos periféricos, mientras que la actividad económica local gira en torno a la construcción y actividades afines a la vez que se ha desarrollado un complejo y extenso sistema de servicios de todo tipo. La propia evolución demográfica es bastante expresiva de este cambio funcional y territorial: dos de estas ciudades han superado el umbral de los 30.000 habitantes en un periodo corto de tiempo. Aunque las transformaciones socioeconómicas impregnan la totalidad del ámbito local, el espacio turístico más relevante de estos municipios se configura al margen de su cabecera principal de población, en el entorno de su tramo costero, donde surge y se estructura a partir de un núcleo marinero, que tuvo casi desde sus orígenes una función veraniega pero que se ha ido expandiendo en los últimos años sobre lo que fue - hasta los años ochenta y noventa del pasado siglo - una llanura de cultivo en la franja costera.

De este modo, llanos de inundación, vegas y tierras de cultivo han mantenido la función agrícola hasta fechas recientes o incluso siguen contando con una aportación relevante por dicha actividad. Aunque la prestación de servicios turísticos y el efecto del mercado de trabajo derivado impregnan la realidad local en todas sus dimensiones, el modelo de poblamiento se caracteriza por el sistema dual entre un núcleo urbano tradicional y los nuevos asentamientos.

El alojamiento viene definido esencialmente por viviendas, ya sea de uso estacional vacacional o segunda residencia, de manera que la vivienda secundaria supera en número a la principal. En ese contexto, las 7.500 plazas de carácter comercial existentes en las diferentes tipologías, supone una parte minoritaria del alojamiento turístico-residencial. Entre 2002 y 2009 ese alojamiento de plazas regladas se incrementa en unas 500 plazas, siendo el grupo de municipios menos activo en la integración en nuevos procesos turísticos alejados de las dinámicas exclusivamente residenciales o vacacionales, si bien en el caso de los municipios murcianos los procesos de diversificación de la oferta de alojamiento son más intensos. En sentido contrario, existen varios proyectos de nuevas urbanizaciones, en ocasiones ligadas a resort-golf (Camposol en Mazarrón, consolidación de Lo Romero en El Pilar de la Horadada) estancadas debido a factores coyunturales pero que, en definitiva, reafirman las dinámicas de producción de espacio turístico-residencial y la clara instrumentación inmobiliaria de las mismas. 
Tabla 3

OFERTA DE ALOJAMIENTO REGLADA 2009 ( $N^{\circ}$ DE PLAZAS)

\begin{tabular}{|l|c|c|c|}
\hline & Hoteles & Hostales & Apartamentos \\
\hline Mazarrón & 708 & 171 & 1.090 \\
\hline El Pilar de la Horadada & 87 & 40 & 1.383 \\
\hline San Javier & 344 & 169 & 422 \\
\hline San Pedro del Pinatar & 999 & 169 & 317 \\
\hline TOTAL & 2.138 & 549 & 3.212 \\
\hline
\end{tabular}

Fuente: Conselleria de Turisme, Generalitat Valenciana. Consejería de Cultura y Turismo, Región de Murcia.

Exponente del cambio funcional y territorial es que estas localidades han doblado la población de derecho, pasando de 56.087 habitantes (1996) a 112.441, en poco más de una década, y especialmente a partir del año 2000, de manera que todas sobrepasan durante el periodo analizado los 20.000 habitantes, e incluso Mazarrón y San Javier, los 30.000. El asentamiento de un voluminoso contingente de población extranjera también refleja en parte esa transformación, caso de la gran presencia de europeos, esencialmente ciudadanos británicos desplazados por motivos de vacaciones de larga duración, aunque no debe perderse de vista la presencia de un importante componente de población extranjera, norteafricana y sudamericana, que ha de explicarse por la persistencia de flujos laborales vinculados al mantenimiento y desarrollo de funciones agrarias en estas poblaciones.

Tabla 4

POBLACIÓN POR NACIONALIDADES (2009)

\begin{tabular}{|l|r|r|r|r|r|r|r|r|}
\hline & Población & Españoles & Extranjeros & Europa & UE & $\begin{array}{r}\text { Reino } \\
\text { Unido }\end{array}$ & Marruecos & Ecuador \\
\hline $\begin{array}{l}\text { Pilar de la } \\
\text { Horadada }\end{array}$ & 22.050 & 11.706 & 10.344 & 7.818 & 7.093 & 4.489 & 1.304 & 829 \\
\hline Mazarrón & 35.221 & 19.091 & 16.130 & 9.523 & 9.245 & 6.950 & 3.377 & 2.326 \\
\hline San Javier & 31.432 & 22.029 & 9.403 & 3.504 & 2.941 & 1.200 & 3.337 & 1.223 \\
\hline $\begin{array}{l}\text { San Pedro del } \\
\text { Pinatar }\end{array}$ & 23.738 & 17.341 & 6.397 & 3.099 & 2.527 & 682 & 2.009 & 879 \\
\hline
\end{tabular}

Fuente: INE.

Las dinámicas que derivan de la actividad de la construcción y afines y del espectacular auge del aparato de servicios (comerciales, bancarios, administrativos, asistenciales) relacionado con el asentamiento de miles de ciudadanos en su término municipal han posibilitado el disparo de los presupuestos municipales desde los 78,6 millones de euros en 2001 a los 144 millones de euros de presupuesto en 2008, lo que arroja una tasa de variación media de $84,4 \%$, crecimientos superiores al $10 \%$ anual, especialmente acusados en San Pedro del Pinatar y San Javier que doblan sus presupuestos municipales en esos ocho años. 


\subsection{Municipios prelitorales con asentamientos y núcleos turístico-residenciales}

Fuente Álamo, Torre Pacheco, Rojales, San Fulgencio, Algorfa y San Miguel de Salinas, son municipios que no cuentan con acceso propio al recurso playa y que han orientado su desarrollo turístico residencial mediante la construcción de urbanizaciones, cuya afectación urbanística se realiza esencialmente - aunque no exclusivamente - sobre espacios agroforestales, topográficamente las tierras más elevadas del término municipal y las que tradicionalmente tuvieron un menor precio del suelo por su reducido valor productivo. No obstante, la carencia de ese recurso básico no ha supuesto que la evolución de los indicadores se manifieste de manera más atenuada, al contrario, se trata del grupo de municipios que muestra mayor intensidad en el crecimiento de algunos de ellos.

En efecto, las urbanizaciones, como se conoce a los asentamientos residenciales, proliferan en estos municipios, ocupando colinas y piedemontes, desde las cuales las viviendas cuentan con perspectivas paisajísticas sobre entornos naturales de calidad (parques naturales, sierras) o sobre el propio mar, aunque también se han ocupado llanuras y espacios de anterior aprovechamiento agrícola. En todo caso se desarrollan al margen del núcleo de población tradicional y tienen capacidad de alojar a miles de residentes, caso de Ciudad Quesada en el municipio de Rojales, que alberga a 15.000 de los 20.000 habitantes empadronados en la localidad, o el de la Marina Oasis en San Fulgencio, con 10.000 de los 12.000 empadronados en el municipio. No es de extrañar, por tanto, que en estos municipios predomine de manera abrumadora el alojamiento en vivienda, vacacional y/o segunda residencia, 14.000 VPUT en Rojales, más 10.000 en San Fulgencio y San Miguel de Salinas, más de 6.000 viviendas finalizadas en Torre-Pacheco entre 2005 y 2007. Este hecho refrenda el desbordamiento urbanístico desde el litoral y pone de manifiesto el progresivo avance de los procesos urbanísticos hacia el prelitoral o interior próximo, incluso repitiendo los conocidos mecanismos de instrumentación de la oferta recreativa, caso de los campos de golf creados en Algorfa y Torre-Pacheco que reproducen el esquema de golf-urbanización, si bien se desarrollan ofertas de alojamiento mixtas con la introducción de alojamiento hotelero de categoría alta.

La oferta de plazas turísticas en hoteles, hostales, apartamentos reglados y camping queda lejos del volumen de la oferta residencial, verdadera locomotora del sistema turístico residencial. Aún así se ha pasado de apenas 234 plazas a comienzos del siglo XXI a 1.300 en 2009 y resulta especialmente destacable la implantación de establecimientos hoteleros de categoría media-alta y alta, como es el caso de los hoteles de cuatro estrellas inaugurados en Rojales y Torre Pacheco y de cinco estrellas en Algorfa, el único hotel existente, y Torre Pacheco, que aparecen asociados a campos de golf.

Tabla 5

OFERTA DE ALOJAMIENTO REGLADA 2009 ( $N^{\circ}$ DE PLAZAS)

\begin{tabular}{|l|c|c|c|c|}
\hline & Hoteles & Hostales & Apartamentos & Campings \\
\hline Algorfa & 144 & - & 123 & - \\
\hline Fuente Álamo de Murcia & 59 & - & - & - \\
\hline Rojales & 230 & - & 54 & - \\
\hline San Fulgencio & - & - & 2 & - \\
\hline San Miguel de Salinas & - & - & 50 & - \\
\hline Torre-Pacheco & 318 & - & 320 & - \\
\hline
\end{tabular}

Fuente: Conselleria de Turisme, Generalitat Valenciana. Consejería de Cultura y Turismo, Región de Murcia. 
El crecimiento de la función residencial, asociada a la construcción de nuevos asentamientos ha supuesto que estos seis municipios hayan incrementado en un $135 \%$ su población de derecho entre el decenio final del siglo XX y la primera década del XXI, pasando de 38.883 habitantes (1996) a 91.392 en poco más de una década. Ese crecimiento proviene en un alto porcentaje del asentamiento de población extranjera que adquiere su segunda residencia. Salvo en Fuente Álamo y Torre Pacheco, la población extranjera supone más del $50 \%$ del total de la población empadronada, incluso alcanza el $76 \%$ en el caso de San Fulgencio, el municipio con más extranjeros residentes sobre el total de su población de toda España. Se trata de residentes europeos, con una fuerte presencia de jubilados británicos en el caso de los municipios alicantinos. Esa composición demográfica se modifica claramente para los dos destinos murcianos, dónde el grupo nacional extranjero más relevante es el de trabajadores ecuatorianos, en relación con la importancia de la actividad agraria en la estructura económica local.

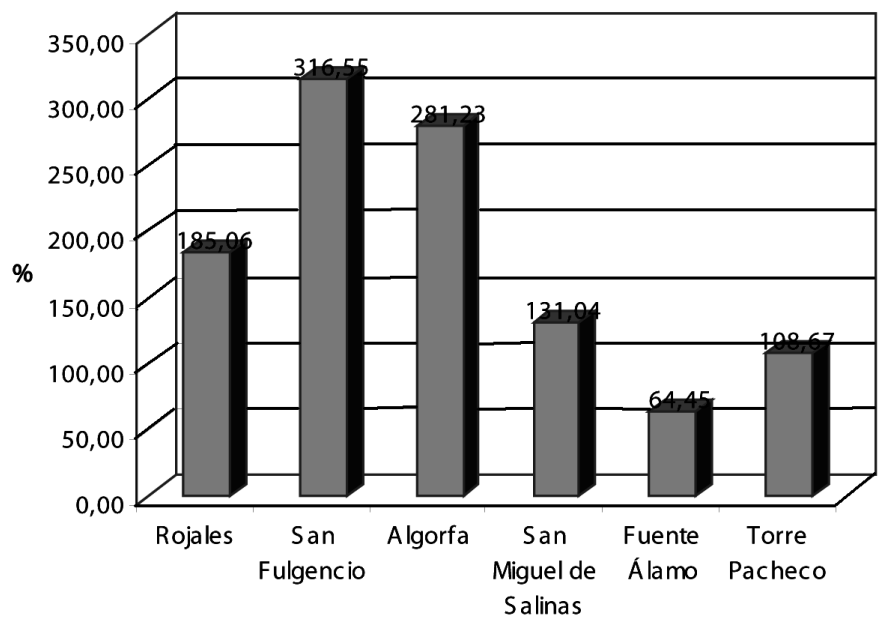

FIgURA 1. Variación de población empadronada (1996-2009).

Fuente: INE.

Tabla 6

POBLACIÓN POR NACIONALIDADES (2009)

\begin{tabular}{|l|r|r|r|r|r|r|}
\hline & $\begin{array}{c}\text { Total } \\
\text { Población }\end{array}$ & Españoles & $\begin{array}{c}\text { Total } \\
\text { Extranjeros }\end{array}$ & $\begin{array}{c}\text { Total } \\
\text { UE }\end{array}$ & $\begin{array}{c}\text { Reino } \\
\text { Unido }\end{array}$ & $\begin{array}{c}\text { Otros grupos } \\
\text { significativos }\end{array}$ \\
\hline Algorfa & 4.346 & 1.311 & 3.035 & 2.941 & 2.536 & \\
\hline Fuente Álamo & 14.876 & 10.332 & 4.544 & 1.346 & 723 & (ECU) 936 \\
\hline Rojales & 20.510 & 5.106 & 15.404 & 12.942 & 8.705 & (ALE) 1.519 \\
\hline San Fulgencio & 12.030 & 2.697 & 9.333 & 8.550 & 6.138 & (ALE) 1.426 \\
\hline San Miguel de Salinas & 8.135 & 2.850 & 5.285 & 4.676 & 3.375 & (ALE)727 \\
\hline Torre-Pacheco & 31.495 & 22.723 & 8.772 & 1.379 & 761 & (ECU) 2.207 \\
\hline
\end{tabular}

Fuente: INE. 
Entre los años 2001 y 2008, este grupo de municipios incrementa en un $170 \%$ sus presupuestos municipales, de manera que desde los 55 millones de euros se pasa a 156 millones. Estos ratios de crecimiento llegan a doblarse como en los casos de San Fulgencio y Torre Pacheco e incluso a triplicarse, caso de Fuente Álamo. Se trata, por tanto, del grupo de municipios que muestra un mayor crecimiento entre los del área estudiada. Estos fuertes incrementos se relacionan con las dinámicas derivadas de la actividad de la construcción y afines, vía Impuesto de Bienes Inmuebles y Licencias de Obra, reproduciendo los mecanismos de financiación municipal que ya se aplicaron desde los años ochenta y noventa en los destinos litorales, y del espectacular auge del aparato de servicios que se vincula con el asentamiento de miles de ciudadanos en su término municipal: comerciales, bancarios, administrativos y asistenciales, entre otros.

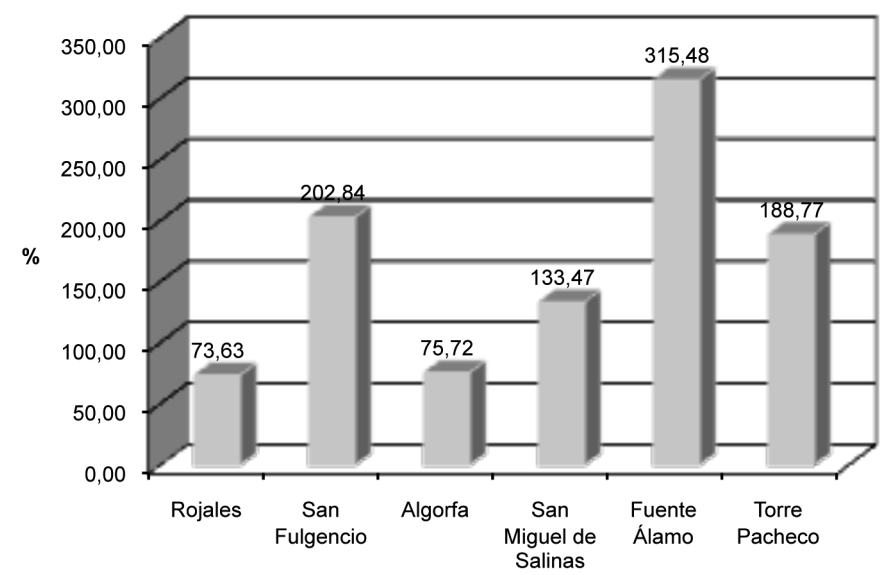

Figura 2. Variación de los presupuestos municipales (2001-2008).

Fuente: Caja España.

\subsection{Ciudades con función turística en su estructura urbana y asentamientos turístico- residenciales costeros}

Las ciudades de Alicante, Elx y Orihuela cuentan, en distinto grado, con función turística en su estructura económica y territorial, aunque no sea ésta la clave de su dinámica de desarrollo local. En Alicante, la dedicación al turismo es un hecho que identifica en buena parte su imagen social, ya desde el siglo XIX, y que tiene su impronta en la estructura urbana, sobre todo en su fachada marítima. La misma planta hotelera de la ciudad testimonia la dedicación y el éxito reciente de la misma, con nuevas dimensiones de turismo urbano. Más reciente, de apenas una década, es el despegue, aún por consolidar, de la actividad que impulsa el turismo urbano en la ciudad de Elx. Mientras que en la ciudad de Orihuela, a pesar de la riqueza de su patrimonio edificado, esta dedicación no se traduce por el momento en una afluencia relevante de visitantes.

Además, estos tres municipios han desarrollado asentamientos en su término municipal para dar cabida a demandas de tipo residencial y turístico, en algunos casos desde los momentos iniciales del crecimiento turístico. Es el caso de Arenales del Sol, en Elx, o el de la Playa de San Juan y la de Urbanova, en Alicante, o el de las grandes urbanizaciones de la costa de Orihuela: La Dehesa de Campoamor, La Zenia, Cabo Roig, Playa Flamenca, entre otras. 
Se trata por tanto de un grupo de municipios en los que el turismo no representa una actividad económica clave aunque cuenta con una larga tradición turística vinculada al turismo litoral, la base de su especialización turística actual, claramente vacacional y asociada al clima y al mar, además del movimiento turístico urbano derivado de las propias funciones económicas urbanas. Progresivamente el sistema turístico ha ido ganando en complejidad, de acuerdo con su propia evolución y la del mercado turístico, para incorporar nuevas ofertas, más especializadas (golf, salud, congresos y otras fórmulas de turismo de negocios colectivo), a lo que habría que añadir una demanda creciente de ocio y esparcimiento metropolitano.

Esa complejidad funcional y la diversidad sectorial en el desarrollo de la misma actividad turística dificultan el análisis de la misma en estos municipios. Se identifican, sin embargo, algunos indicadores que permiten una aproximación a la realidad territorial turística de estos destinos.

En cuanto a la capacidad de alojamiento, el peso específico del parque de viviendas de potencial uso turístico cobra especial importancia a tenor del rango urbano de sus ciudades. De este modo, se estima para este conjunto en el año 2007 un total de casi 105.000 VPUT (el $51 \%$ en la capital provincial) derivada del desarrollo inmobiliario y del uso vacacional de los inmuebles, generalmente como segunda residencia. En cuanto a la oferta de alojamiento reglado se advierte claramente una notable dinámica en los últimos años en la creación de alojamiento comercial, incrementándose desde las casi 12.000 plazas en el año 2000 a 16.500 en el año 2009. Especial relevancia tiene el crecimiento de la oferta de plazas hoteleras, que pasan de las 5.870 del año 2000 hasta las 9.368 del año 2009, debido al impulso del turismo urbano (vacacional y de negocios) en Elx y Alicante. De hecho, salvo la excepción de un hotel en la ciudad de Orihuela y otro en su área costera, asociado al golf, el resto de nuevos establecimientos creados aparecen en las dos mayores ciudades, dentro del propio núcleo urbano o incluso en las nuevas áreas industriales, como ocurre en Elx. Incluso en el caso de la capital alicantina se advierte un cierto sobredimensionamiento de la oferta de alojamiento en hoteles.

Tabla 7

OFERTA DE ALOJAMIENTO REGLADA 2009 ( $N^{\circ}$ DE PLAZAS)

\begin{tabular}{|l|c|c|c|c|}
\hline & Hoteles & Hostales & Apartamentos & Campings \\
\hline Alicante & 6.982 & 502 & 1.258 & - \\
\hline Elx & 1.414 & 415 & 362 & 1.215 \\
\hline Orihuela & 972 & 70 & 3.245 & - \\
\hline
\end{tabular}

Fuente: Conselleria de Turisme. Generalitat Valenciana.

Otros indicadores como el crecimiento demográfico testimonian la menor influencia de las dinámicas asociadas al turismo y las fórmulas vacacionales y residenciales sobre estos espacios urbanos. Estas tres ciudades pasan de concentrar 520.000 habitantes en 1995 a 651.000 en 2009, con una tasa de variación media del 20\%, lo que supone el menor incremento relativo dentro de los municipios de la MCT objeto de análisis, aunque los tres incluidos han conocido crecimientos importantes. La cuestión es que no experimentan de modo tan directo los efectos del tirón de la construcción, asociada a la promoción de viviendas vacacionales o para atraer residentes permanentes, si se compara con lo que ha 
acontecido en los municipios volcados por completo a esta función. Resulta indicativo que sólo en el caso de Orihuela el porcentaje de población extranjera supera el $40 \%$ del total, por el efecto de sus asentamientos costeros.

Por lo que atañe a los presupuestos municipales, los Ayuntamientos de Alicante, Elx y Orihuela han pasado de administrar 395 millones de euros en 2001, hasta los 574,2 en 2008 , lo que significa una variación del $45 \%$ en el crecimiento de esta variable que actúa como indicador de la actividad económica local. En términos comparativos con el resto de municipios del área MCT, se trata de un crecimiento bastante más bajo, pero no deja de ser relevante ya que se ha potenciado el papel de las mayores ciudades, que pasan a ser grandes concentraciones de servicios urbanos de rango superior y actividades económicas que no dependen de forma lineal, al menos en bastantes casos, del tirón de la construcción, que es la única actividad de elevado dinamismo de una buena parte del resto de municipios del área.

\section{El gasto de agua asociado a las tipologías turístico-teritoriales}

Es necesario reconocer de partida las dificultades estadísticas y conceptuales en torno al análisis de los usos turísticos del agua. Por una parte existe la dificultad de separar los consumos estrictamente turísticos de los derivados del abastecimiento de poblaciones en general. Por otra, la propia diversidad tipológica y funcional del alojamiento turístico, desde la oferta reglada a las segundas residencias, limita notablemente las posibilidades del estudio de las peculiaridades de estos consumos.

La disponibilidad y gestión de los recursos hídricos para usos turísticos constituye uno de los factores clave que condicionan el desarrollo del turismo y, por otra parte, es un componente de gran influencia sobre el atractivo e incluso el mantenimiento de los destinos turísticos, máxime en espacios como los que constituyen el ámbito geográfico del estudio, donde el turismo tiene un carácter estratégico en las estructuras económicas al tiempo que se trata de territorios que dependen en alto grado de recursos de agua alóctonos.

En primera aproximación el consumo de agua en los municipios abastecidos por la Mancomunidad de los Canales del Taibilla, el gasto de agua ha pasado de $192,38 \mathrm{hm}^{3}$ en 1998 hasta los 205,71 de 2009. Parte de ese incremento debe relacionarse con la extensión de los destinos turísticos preexistentes y con la creación de espacios turísticos ex novo. En este sentido, en el área de estudio predominan modelos urbanos relacionados con fórmulas vacacionales y la segunda residencia, alejadas de los destinos turísticos en sentido estricto. Clima, accesibilidad, bajos tipos de interés bancario, redes comerciales y de distribución del producto inmobiliario y la eclosión de compañías aéreas de bajo coste en los últimos años, junto con la preferencia de utilizar vivienda propia y el crecimiento del grupo de jubilados de Europa del Norte, han sido las causas que han justificado el desarrollo de estos asentamientos.

No obstante, la heterogeneidad tipológica, que se define tanto desde la oferta como desde la demanda, de los distintos destinos tiene su manifestación sobre los consumos de agua, fundamentalmente en lo que se refiere a la magnitud de los volúmenes suministrados y las tendencias de futuro, y a la peculiaridad que supone el consumo estacional de esos recursos que implica la infrautilización durante temporadas de infraestructuras que han sido necesariamente sobredimensionadas en el momento de su construcción.

Cada uno de los grupos de municipios identificados en este estudio ha incrementado notablemente los consumos hídricos desde los años noventa. Los principales destinos con función turística del área servida por la MCT pasan de 80.59 hm³ $^{3}$ en el año 1999 a consumir 95,66 una década después lo que ha supuesto un incremento global en torno al $18,7 \%$. Sin embargo, ese aumento del consumo no ha sido homogéneo. Los destinos 
turísticos costeros, que concentraron las fases expansivas de los años ochenta y noventa del pasado siglo $\mathrm{XX}$, han reducido la intensidad de ese crecimiento e incluso se percibe una disminución de las demandas desde la mitad de la presente década. Similar ha sido el proceso en las ciudades con función turística, si bien en este es el caso donde más difícil resulta discernir entre usos turísticos y no turísticos dada la complejidad funcional de estas ciudades. En sentido contrario, las tipologías definidas por municipios en los que se han implantado asentamientos urbano-turísticos desarrollados ex novo y al margen de las cabeceras municipales presentan incrementos superiores, de hasta el $40 \%$ en el caso de los municipios prelitorales y la disminución de las demandas se percibe mucho más atenuada. En esta línea son ampliamente conocidos los diferentes efectos que sobre el gasto del agua tienen los distintos modelos de implantación territorial turística (Vera, 2006; Rico, 2007) desde los asentamientos dispersos, extensivos y difusos, pasando por espacios concentrados y distribuidos en «mancha de aceite» entre los que se pueden catalogar estos centros vacacionales y de segunda residencia, hasta los ejemplos de ciudad turística concentrada.

Tabla 8

CONSUMOS DE AGUA POR TIPOLOGÍAS TURÍSTICAS (HM³)

\begin{tabular}{|l|c|r|r|c|}
\hline & $\mathbf{1 9 9 9}$ & $\mathbf{2 0 0 4}$ & $\mathbf{2 0 0 9}$ & $\begin{array}{r}\text { Variación } \\
\mathbf{1 9 9 9 - 2 0 0 9}\end{array}$ \\
\hline Destinos turísticos costeros & 19,98 & 25,27 & 23,35 & 16,86 \\
\hline $\begin{array}{l}\text { Municipios litorales con } \\
\text { asentamientos y núcleos } \\
\text { turísticos residenciales }\end{array}$ & 10,14 & 12,84 & 13,34 & 31,47 \\
\hline $\begin{array}{l}\text { Municipios prelitorales con } \\
\text { asentamientos y núcleos } \\
\text { turísticos residenciales }\end{array}$ & 7,22 & 9,67 & 10,13 & 40,36 \\
\hline $\begin{array}{l}\text { Ciudades con función } \\
\text { turística }\end{array}$ & 43,25 & 51,93 & 48,84 & 12,94 \\
\hline TOTAL & 80,59 & 99,71 & 95,66 & 18,70 \\
\hline
\end{tabular}

Fuente: Mancomunidad de los Canales del Taibilla.

Las causas que explican el desarrollo de los modelos de mayor incremento de los consumos en los últimos años han de relacionarse con la saturación urbanística y la consiguiente falta de suelo que caracteriza a los espacios turísticos de primera generación. Así, en destinos costeros, el agotamiento del suelo y el encarecimiento del mismo justifican por otra parte la mayor intensidad de los procesos de expansión y difusión del residencialismo hacia los entornos prelitorales, como áreas de desbordamiento de los destinos y asentamientos costeros. Asimismo, la progresiva consolidación de demandas que buscan complementar la estancia con la posibilidad de practicar deportes, fundamentalmente el golf, fomenta la aparición de nuevos asentamientos de «urbanización-golf» que reproducen los conocidos esquemas de instrumentación inmobiliaria de la oferta recreativa, con amplias repercusiones sobre los consumos de agua.

En última instancia, la evolución a medio plazo a partir de la contracción de las demandas manifestada de manera generalizada en los últimos años dependerá, de un lado, 


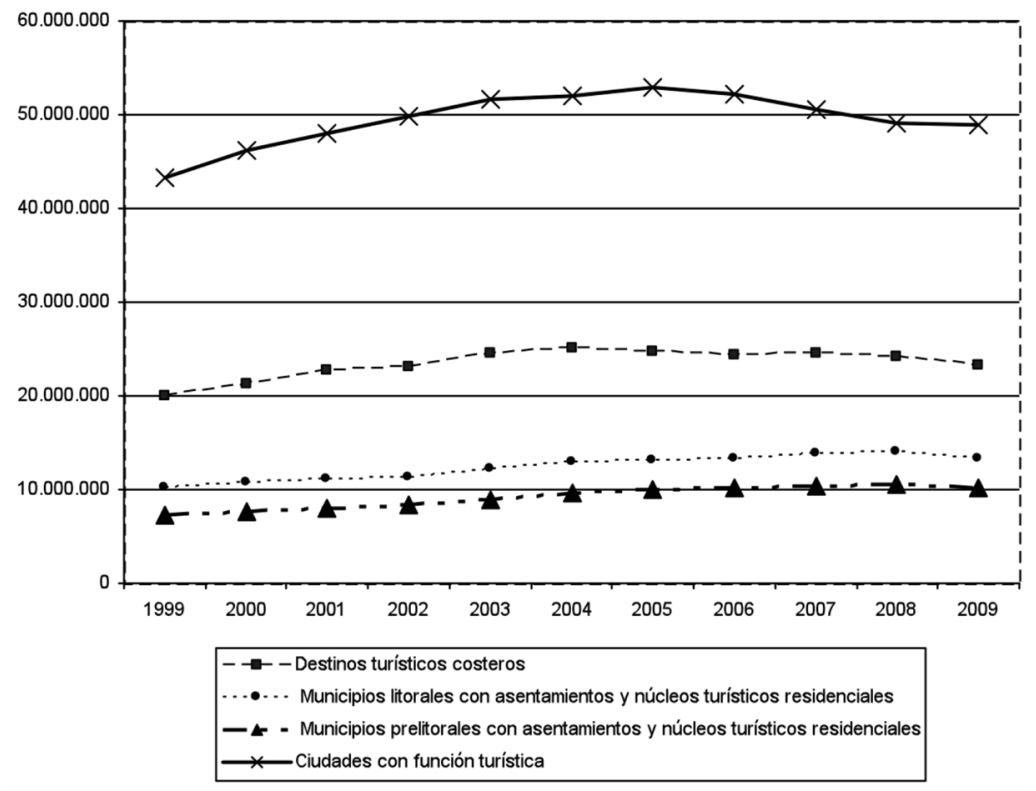

FIgURA 3. Evolución consumos de agua por tipologías turísticas (m³) 1999-2009 Fuente: Mancomunidad de los Canales del Taibilla.

de como se produzca el fin de la actual crisis financiera y de crecimiento, así como de la consolidación de nuevos competidores, en los que emerge la función residencial, especialmente en el Mediterráneo Oriental (Chipre, Turquía) y Norte de África (Marruecos). Si se continúa dando respuesta a los impulsos de la demanda y se resuelve la actual incógnita de la financiación de nuevas operaciones no cabe duda que se continuará con el auge del residencialismo, proliferando actuaciones que supongan la enajenación de más bolsas de suelo para su cambio de su uso e intensificando la presión sobre los recursos hídricos.

El carácter temporal de las prácticas turísticas influye el consumo estacional que se realiza del agua, de manera que deben conjugarse momentos de gran punta en el consumo y suministro con periodos de mínimos definidos por los consumos exclusivamente residenciales. Independientemente de los efectos de esa estacionalidad sobre las estructuras económicas locales y sobre las empresas turísticas, desde el punto de vista del abastecimiento del recurso, obliga a gestionar la irregularidad de las demandas y al mantenimiento de infraestructuras de abastecimiento y distribución sobredimensionadas. No obstante, la reducción de esos índices mediante el desarrollo de políticas de desestacionalización supondrá un incremento de los consumos en meses que eran de bajo consumo (Vera, 2006) y por tanto de los totales.

En este caso, los valores máximos corresponden al grupo de los destinos costeros, resultado de la existencia de numerosas plazas de alojamiento ocupadas exclusivamente en periodos vacacionales, comercializadas a través de circuitos alegales. Los menores índices por su parte aparecen registrados en las grandes ciudades y en los municipios prelitorales. En las primeras, el consumo estacional queda diluido en la complejidad funcional y la diversidad de usos consuntivos que caracterizan a estos espacios urbanos, mientras que los reducidos valores en los municipios prelitorales con asentamientos turístico-residenciales se explican por el marcado carácter residencial de de los mismos. 


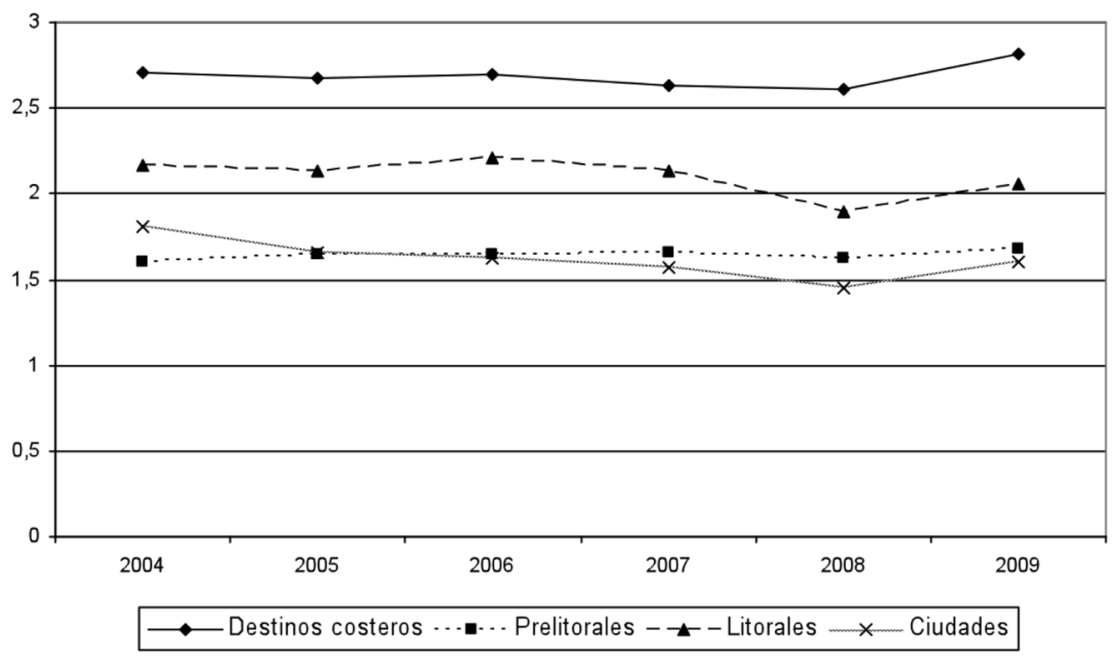

FIGURA 4. Evolución índice de estacionalidad tipologías turísticas 2004-2009. Fuente: Mancomunidad de los Canales del Taibilla.

La tendencia que se venía identificando durante el siglo XXI era la reducción de esa estacionalidad en los consumos, relacionada con una fijación de la población residente y la prolongación de las estancias. Así en los años noventa Torrevieja, como ejemplo paradigmático de esta tipología, conocía valores de estacionalidad en torno a 3,5. En el último año se percibe un aumento generalizado del indicador que requeriría de un análisis en profundidad de los componentes que participan para su comprensión, entre los cuales puede encontrarse la contracción de estancias ligadas a la crisis económica.

\subsection{Atenuación del ritmo de crecimiento de las demandas hídricas y transición hacia pautas de consumo residenciales en los destinos turísticos costeros}

Las intensas dinámicas inmobiliarias y sus efectos sobre el incremento de las unidades de vivienda de uso vacacional y, en definitiva, sobre la creación de nuevos espacios urbano turísticos tienen notables repercusiones sobre los consumos hídricos de estos destinos. En efecto, las cinco entidades locales que conforman el grupo consumen en 2009 prácticamente el 10,8\% del total de agua facturada por la MCT mientras en 1994 consumían el 8,75\%. Durante el periodo, 1999-2009, el incremento del consumo ha sido del 16,8\%, con un pico máximo en 2004 en que se alcanza un consumo de $25 \mathrm{hm}^{3}$ que se verán paulatinamente reducidos hasta los 23,3 del año 2009, descenso que se relaciona con una contracción de las demandas debido a una mayor eficacia en la gestión de estos recursos en su distribución en baja y, en parte, a la crisis económica iniciada 2008. Los incrementos en los consumos registrados desde al menos mitad de los años noventa resultan un claro indicador del proceso de construcción de nuevas unidades urbanas en relación con demandas de tipo residencial y turístico, especialmente en los municipios de Torrevieja, que pasa de un consumo en 6,3 $\mathrm{Hm}^{3}$ en 1994 a un pico de 10,4 $\mathrm{Hm}^{3}$ en 2003, Guardamar del Segura y Los Alcázares, con incrementos de consumo próximos al $50 \%$ en los últimos tres lustros. 
Tabla 9

CONSUMOS HÍDRICOS DE LOS DESTINOS TURÍSTICOS COSTEROS DEL ÁREA MCT 1994-2009 (M3)

\begin{tabular}{|l|c|c|c|c|}
\hline & \multicolumn{1}{|c|}{$\mathbf{1 9 9 9}$} & $\mathbf{2 0 0 4}$ & \multicolumn{1}{c|}{$\mathbf{2 0 0 9}$} & Variación 1999-2009 \% \\
\hline Águilas & 2.840 .830 & 3.402 .875 & 3.165 .822 & 11,44 \\
\hline $\begin{array}{l}\text { Guardamar del } \\
\text { Segura }\end{array}$ & 1.599 .344 & 1.937 .785 & 1.832 .490 & 14,58 \\
\hline Los Alcázares & 1.665 .008 & 2.233 .680 & 2.095 .836 & 25,88 \\
\hline Santa Pola & 3.090 .160 & 4.091 .090 & 3.819 .211 & 23,59 \\
\hline Torrevieja & 8.165 .857 & 10.305 .720 & 9.381 .320 & 14,88 \\
\hline La Manga & $2.621 .133 *$ & 3.101 .431 & 3.057 .224 & 16,63 \\
\hline TOTAL & 19.982 .332 & 25.072 .581 & 23.351 .903 & 16,86 \\
\hline
\end{tabular}

Fuente: Mancomunidad de los Canales del Taibilla.

* Para el caso de los datos manejados en el sector de La Manga perteneciente al municipio de Cartagena, se ha obtenido una estimación a partir de datos facilitados por la Mancomunidad de los Canales del Taibilla de $1.077 .330 \mathrm{~m}^{3}$.

Por otra parte, se ha señalado el factor de la estacionalidad entre las peculiaridades que presenta el consumo del agua en espacios turísticos y vacacionales y que tienen amplias repercusiones sobre la gestión del recurso. En el caso de estos destinos turísticos costeros, la atracción generada sobre determinados mercados de demanda que adquieren un comportamiento «casi residencial» en sus estancias - tercera edad, razones laborales - ha supuesto la suavización de los índices de estacionalidad que identifican la irregularidad de esos consumos ${ }^{7}$, aunque se detectan todavía valores muy elevados en La Manga y Los Alcázares.

Tabla 10

EVOLUCIÓN DEL ÍNDICE DE ESTACIONALIDAD (2004-2009)

\begin{tabular}{|l|r|r|r|r|r|r|}
\hline & $\mathbf{2 0 0 4}$ & $\mathbf{2 0 0 5}$ & $\mathbf{2 0 0 6}$ & $\mathbf{2 0 0 7}$ & $\mathbf{2 0 0 8}$ & $\mathbf{2 0 0 9}$ \\
\hline Águilas & 1,66 & 1,75 & 1,79 & 1,83 & 1,70 & 1,72 \\
\hline Guardamar del Segura & 2,68 & 2,68 & 2,76 & 2,65 & 2,87 & 2,88 \\
\hline Los Alcázares & 3,48 & 3,53 & 3,29 & 3,06 & 2,96 & 3,32 \\
\hline Santa Pola & 2,81 & 2,82 & 2,56 & 2,64 & 2,70 & 2,88 \\
\hline Torrevieja & 2,52 & 2,40 & 2,45 & 2,35 & 2,33 & 2,55 \\
\hline La Manga & 4,46 & 4,87 & 5,47 & 4,70 & 4,84 & 5,39 \\
\hline TOTAL & 2,71 & 2,68 & 2,70 & 2,63 & 2,61 & 2,82 \\
\hline
\end{tabular}

Elaboración propia a partir de la Mancomunidad de los Canales del Taibilla.

7 A mediados de los años noventa del pasado siglo XX municipios integrados en esta tipología como Torrevieja o Guardamar del Segura presentaban índices de estacionalidad superiores a 3,5. 
4.2. Incremento continuado de las demandas de agua en los municipios litorales con asentamientos turísticos en su franja costera

El intenso crecimiento demográfico identificado para este conjunto de municipios aparece claramente plasmado en la evolución de los consumos de agua. Estas entidades locales han incrementado sus consumos hídricos una media de un $44 \%$ desde mitad de los años noventa, pasando el conjunto de estas entidades de 10 a 13,3 $\mathrm{hm}^{3}$. La tendencia al alza en los consumos se intensifica especialmente a partir de los años finales de la década de los noventa y se justifican, en parte, con usos consuntivos turísticos-residenciales. Por otro lado, es de destacar que, salvo en el caso de San Pedro de Pinatar, desde 2005 se detecta una tendencia hacia la estabilización en los consumos que se transforma en un descenso de las demandas en el año 2009, en relación, al menos parcialmente, con la actual coyuntura de crisis inmobiliaria.

Tabla 11

CONSUMOS HÍDRICOS DE LOS DESTINOS VACACIONALES LITORALES DEL ÁREA MCT 1999-2009 $\left(M^{3}\right)$

\begin{tabular}{|l|c|c|c|c|c|}
\hline & $\mathbf{1 9 9 9}$ & $\mathbf{2 0 0 5}$ & $\mathbf{2 0 0 9}$ & $\begin{array}{c}\text { Variación } \\
\mathbf{1 9 9 9 - 2 0 0 9} \\
\mathbf{\%}\end{array}$ & $\begin{array}{c}\text { Variación } \\
\mathbf{2 0 0 5 - 2 0 0 9} \\
\mathbf{\%}\end{array}$ \\
\hline $\begin{array}{l}\text { El Pilar de la } \\
\text { Horadada }\end{array}$ & 2.178 .366 & 2.752 .945 & 2.445 .820 & 12,28 & $-11,16$ \\
\hline San Javier & 2.579 .826 & 3.114 .553 & 3.361 .736 & 30,31 & 7,94 \\
\hline $\begin{array}{l}\text { San Pedro del } \\
\text { Pinatar }\end{array}$ & 2.179 .863 & 2.645 .538 & 3.304 .846 & 51,61 & 24,92 \\
\hline Mazarrón & 3.206 .129 & 4.590 .393 & 4.224 .483 & 31,76 & $-7,97$ \\
\hline TOTAL & 10.144 .184 & 13.103 .429 & 13.336 .885 & 31,47 & 1,78 \\
\hline
\end{tabular}

Fuente: Mancomunidad de los Canales del Taibilla.

Tabla 12

EVOLUCIÓN DEL ÍNDICE DE ESTACIONALIDAD (2004-2009)

\begin{tabular}{|l|c|c|c|c|c|c|}
\hline & $\mathbf{2 0 0 4}$ & $\mathbf{2 0 0 5}$ & $\mathbf{2 0 0 6}$ & $\mathbf{2 0 0 7}$ & $\mathbf{2 0 0 8}$ & $\mathbf{2 0 0 9}$ \\
\hline $\begin{array}{l}\text { El Pilar de la } \\
\text { Horadada }\end{array}$ & 2,53 & 2,20 & 2,64 & 2,71 & 2,44 & 2,49 \\
\hline San Javier & 2,15 & 2,06 & 2,21 & 1,69 & 1,83 & 2,04 \\
\hline $\begin{array}{l}\text { San Pedro } \\
\text { del Pinatar }\end{array}$ & 2,08 & 2,22 & 1,99 & 2,16 & 1,84 & 1,99 \\
\hline Mazarrón & 2,06 & 2,08 & 2,13 & 2,18 & 1,71 & 1,89 \\
\hline TOTAL & 2,17 & 2,13 & 2,21 & 2,13 & 1,90 & 2,06 \\
\hline
\end{tabular}

Elaboración propia a partir de Mancomunidad de los Canales del Taibilla. 
El comportamiento estacional de los consumos se sitúa en todos casos en torno al doble de consumo en los picos de verano en comparación al mínimo invernal. En el caso de El Pilar de la Horadada esos valores se incrementan en un $25 \%$ dado que es el municipio que cuenta con un mayor volumen de oferta de uso estacional, con cerca de 30.000 plazas en viviendas de uso secundario, fundamentalmente en los asentamientos del litoral (Mil Palmeras, Torre de la Horadada) y que resulta de una mayor antigüedad en la irrupción de los procesos de creación de espacios urbano-turísticos.

\subsection{El disparo del gasto de agua en el área prelitoral ante la expansión residencial-turística}

En clara correspondencia con el disparo del crecimiento inmobiliario-turístico, en forma de asentamientos residenciales de nueva planta, este grupo de municipios presenta el crecimiento más acelerado en los consumos hídricos dentro del área MCT, ya que pasan de consumir 4,5 millones de $\mathrm{m}^{3}$ en 1994 a 10,1 en 2009. Es decir, la tasa de variación media alcanza el $122 \%$, con casos espectaculares como el de Algorfa que en ese periodo triplica los consumos, en relación con las operaciones inmobiliarias surgidas en torno al golf urbanización. En el momento actual representan el 5\% del agua facturada por la MCT a las entidades locales a las que abastece, con la particularidad de que únicamente en el último año (2009) se percibe una disminución en el consumo, hecho que en el resto de los municipios estudiados venía manifestándose desde inicio y mediados del decenio de 2000.

Tabla 13

CONSUMOS HÍDRICOS DE LOS DESTINOS VACACIONALES PRELITORALES DEL ÁREA MCT 1994-2009 $\left(M^{3}\right)$

\begin{tabular}{|c|c|c|c|c|c|}
\hline & 1994 & 1999 & 2004 & 2009 & $\begin{array}{c}\text { Variación 1994-2009 } \\
\%\end{array}$ \\
\hline Algorfa & 89.380 & 111.740 & 164.360 & 378.940 & 323,97 \\
\hline Fuente Álamo & 1.533 .081 & 1.709 .501 & 2.162 .061 & 2.428 .245 & 58,39 \\
\hline Rojales & 975.384 & 1.248 .970 & 2.029 .372 & 1.928 .610 & 97,73 \\
\hline San Fulgencio & 576.300 & 678.130 & 1.073 .230 & 971.360 & 68,55 \\
\hline $\begin{array}{l}\text { San Miguel de } \\
\text { Salinas } \\
\end{array}$ & 361.098 & 466.330 & 561.040 & 554.650 & 53,60 \\
\hline Torre Pacheco & 2.568 .398 & 3.003 .856 & 3.684 .507 & 3.870 .411 & 50,69 \\
\hline TOTAL & 4.551 .957 & 7.218 .527 & 8.919 .969 & 10.132 .216 & 122,59 \\
\hline
\end{tabular}

Fuente: Mancomunidad de los Canales del Taibilla.

Por otra parte, los índices de estacionalidad establecidos a partir de los consumos hídricos son los más reducidos de los municipios vacacionales del área de estudio al margen lógicamente de las tres grandes ciudades incluidas en el grupo cuarto. Este indicador se sitúa en torno al valor de 1,6 como media para el conjunto de los destinos prelitorales, derivado del perfil de los residentes de larga duración, si bien se detecta en algunos casos, Algorfa o San Miguel de Salinas, una tendencia ascendente. 
Tabla 14

EVOLUCIÓN DEL ÍNDICE DE ESTACIONALIDAD (2004-2009)

\begin{tabular}{|l|c|r|r|r|r|r|}
\hline & $\mathbf{2 0 0 4}$ & \multicolumn{1}{|c|}{$\mathbf{2 0 0 5}$} & \multicolumn{1}{|c|}{$\mathbf{2 0 0 6}$} & \multicolumn{1}{c|}{$\mathbf{2 0 0 7}$} & \multicolumn{1}{c|}{$\mathbf{2 0 0 8}$} & \multicolumn{1}{c|}{$\mathbf{2 0 0 9}$} \\
\hline Algorfa & 1,59 & 1,75 & 2,19 & 2,00 & 1,90 & 2,56 \\
\hline Fuente Álamo & 1,38 & 1,48 & 1,47 & 1,53 & 1,48 & 1,50 \\
\hline Rojales & 2,10 & 2,03 & 2,10 & 2,06 & 1,93 & 2,12 \\
\hline San Fulgencio & 2,01 & 1,94 & 2,12 & 1,90 & 1,95 & 2,11 \\
\hline San Miguel de Salinas & 1,71 & 1,60 & 1,48 & 1,73 & 1,46 & 1,97 \\
\hline Torre Pacheco & 1,40 & 1,50 & 1,48 & 1,48 & 1,48 & 1,41 \\
\hline TOTAL & 1,60 & 1,65 & 1,65 & 1,66 & 1,62 & 1,68 \\
\hline
\end{tabular}

Elaboración propia a partir de Mancomunidad de los Canales del Taibilla.

\subsection{Eficiencia en la gestión de los recursos de agua y crecimiento de la función turística} en las ciudades

El hecho de estar integradas en este grupo algunas de las mayores ciudades del área de estudio, con más de 650.000 habitantes permanentes, justifica que el agua facturada por la MCT alcance casi una cuarta parte de los consumos del área de estudio. A destacar que para el periodo que va de 1994 a 2009 el consumo ha pasado de $39 \mathrm{hm}^{3}$ a $48,8 \mathrm{hm}^{3}$, con una de variación del 20\%. Es, por tanto, el grupo que menos crece en términos relativos y, a la vez, el que más ha reducido sus consumos totales ya que en 2005 eran $52,9 \mathrm{hm}^{3}$, lo que da idea de los esfuerzos y resultados conseguidos en la gestión de los recursos de agua, a pesar de haber seguido el crecimiento urbano y turístico, y fundamentalmente en el acusado descenso de las demandas.

Tabla 15

CONSUMOS HÍDRICOS DE LAS CIUDADES CON FUNCIÓN TURÍSTICA DEL ÁREA MCT 1994-2009 $\left(M^{3}\right)$

\begin{tabular}{|l|c|c|c|c|c|c|}
\hline & $\mathbf{1 9 9 4}$ & $\mathbf{1 9 9 9}$ & $\mathbf{2 0 0 4}$ & $\mathbf{2 0 0 9}$ & $\begin{array}{c}\text { Variación } \\
\mathbf{1 9 9 4 - 2 0 0 9} \\
\mathbf{\%}\end{array}$ & $\begin{array}{c}\text { Variación } \\
\mathbf{2 0 0 4 - 2 0 0 9} \\
\mathbf{\%}\end{array}$ \\
\hline Alicante & 19.719 .717 & 21.160 .481 & 26.147 .670 & 24.013 .900 & 21,78 & $-8,16$ \\
\hline Elche & 14.032 .054 & 15.255 .730 & 15.254 .807 & 15.045 .900 & 7,23 & $-1,37$ \\
\hline Orihuela & 5.192 .801 & 6.830 .147 & 10.526 .431 & 9.780 .550 & 88,35 & $-7,09$ \\
\hline TOTAL & 38.946 .566 & 43.246 .358 & 51.930 .912 & 48.842 .359 & 25,41 & $-5,95$ \\
\hline
\end{tabular}

Fuente: Mancomunidad de los Canales del Taibilla.

Los índices de estacionalidad reflejan la diversidad funcional de estos espacios y la menor impronta de la actividad turística. Sólo en el caso de Orihuela se advierte un comportamiento estacional suficientemente marcado en relación con el mayor desarrollo vacacional de los asentamientos turístico-residenciales implantados en su espacio litoral 
(Playa Flamenca, La Zenia, Cabo Roig, La Regia, Dehesa de Campoamor) y prelitoral en torno a operaciones de golf-urbanización (Villamartín, Campoamor, Las Ramblas) iniciadas ya desde los años setenta.

Tabla 16

EVOLUCIÓN DEL ÍNDICE DE ESTACIONALIDAD

(2004-2009)

\begin{tabular}{|l|r|r|r|r|r|r|}
\hline & \multicolumn{1}{|c|}{$\mathbf{2 0 0 4}$} & \multicolumn{1}{c|}{$\mathbf{2 0 0 5}$} & \multicolumn{1}{|c|}{$\mathbf{2 0 0 6}$} & $\mathbf{2 0 0 7}$ & \multicolumn{1}{c|}{$\mathbf{2 0 0 8}$} & \multicolumn{1}{c|}{$\mathbf{2 0 0 9}$} \\
\hline Alicante & 1,96 & 1,77 & 1,54 & 1,47 & 1,49 & 1,68 \\
\hline Elx & 1,47 & 1,37 & 1,53 & 1,46 & 1,18 & 1,28 \\
\hline Orihuela & 1,99 & 1,89 & 2,02 & 1,99 & 1,81 & 1,96 \\
\hline TOTAL & 1,81 & 1,66 & 1,62 & 1,57 & 1,45 & 1,60 \\
\hline
\end{tabular}

Elaboración propia a partir de Mancomunidad de los Canales del Taibilla.

\section{Conclusiones}

La Región de Murcia y el sur de Alicante forman parte de uno de los ámbitos naturales más secos de Europa, lo que confiere un carácter estratégico a los recursos de agua para el desarrollo de la población y de sus actividades económicas. Pero las mismas condiciones térmicas y de insolación otorgan a este espacio una posición privilegiada para el desarrollo de las actividades turísticas. De este modo, en los últimos treinta años se produce un espectacular crecimiento demográfico y económico que se ha basado, en gran medida, en la actividad turístico-residencial. La actividad económica del área MCTA gira, en buena medida, en torno al turismo y los procesos de construcción y promoción de viviendas, asociados tanto a la fijación de población residente, procedente de otros países y regiones, como a la ocupación estacional de los alojamientos. Dependen de estos procesos, en mayor o menor grado, todos los municipios localizados en la franja litoral y en el espacio prelitoral, aunque la dinámica del mercado de trabajo generado por los servicios y la construcción afecta, de modo más o menos directo, a la práctica totalidad de las entidades locales de este espacio. Por tanto, la progresiva integración de las entidades municipales en el gran sistema de abastecimiento de la Mancomunidad de los Canales del Taibilla ha sido clave para el desarrollo territorial.

De este modo, ante el incremento de municipios que se han ido integrando en la Mancomunidad y la necesidad creciente de abastecimiento a las poblaciones mancomunadas, las aportaciones iniciales del río Taibilla se han visto completadas, desde los años sesenta del pasado siglo con aguas del río Segura, aguas subterráneas, aguas del trasvase Tajo-Segura, aguas de otras procedencias (mercados de agua) y, en la última etapa, aguas desaladas. En este sentido, la cuestión de los costes actuales del agua desalada es determinante para mantener la actual aportación de las aguas del trasvase Tajo-Segura.

Las continuas inversiones realizadas en la Mancomunidad de los Canales del Taibilla han permitido configurar uno de los mayores complejos hidráulicos de España en el abastecimiento de agua potable, con una capacidad de suministro de $325 \mathrm{hm}^{3} / a$ ano, esto es, un volumen que supera en un $40 \%$ el nivel de consumo actual y en un $25 \%$ a la demanda futura prevista en el Plan Hidrológico de la cuenca del Segura. 
Hay que indicar que los años iniciales de la nueva centuria han coincidido con un momento álgido de la expansión inmobiliario-turística en el litoral mediterráneo español, que se ha vivido con intensidad en el litoral murciano y sur de Alicante, aunque la crisis económica iniciada en 2007 ha supuesto una ruptura en la tendencia de crecimiento de consumo de agua, al ir acompañada de una brusca caída de la actividad inmobiliaria.

La modalidad de alojamiento residencial propia del litoral es la que más ha influido en el consumo de agua de la totalidad de municipios abastecidos por la MCT tanto en la Región de Murcia como en el área abastecida en la provincia de Alicante. De hecho, la garantía del abastecimiento es una de las claves esenciales que sustentan el modelo económico y que permiten hablar de una actividad económica estratégica para este ámbito. La misma estacionalidad en el gasto de agua es expresiva de la relación lineal con el sistema turístico dominante.

El escenario futuro hace prever un descenso en el ritmo de creación de nuevas ofertas residenciales, en lo que influye la situación económica global, la caída de ventas y la gran cantidad de viviendas en promociones que no han sido vendidas. Pero, en aras de la propia calidad del destino turístico y de su futura competitividad, habrá que seguir garantizando los abastecimientos actuales, en calidad y cantidad suficientes. Por tanto, aunque es previsible que la situación futura no se caracterice por grandes incrementos del parque de viviendas vacacionales, como los ocurridos en la década anterior, si debe considerarse el efecto de la tendencia hacia un uso más frecuente de las viviendas vacacionales, lo que supondrá una tendencia al incremento del consumo de agua. Sin olvidar que debe garantizarse el abastecimiento de agua a todos los asentamientos construidos en el periodo anterior. Por lo demás, no hay que perder de vista que hay aprobados proyectos para construir grandes complejos turísticos, larvados en la situación actual de crisis, pero que si se llevan a cabo en los próximos años, sumarán demandas de agua con una considerable repercusión en el gasto total.

Las modalidades de turismo de interior y su reflejo en el consumo de agua, en el momento actual, apenas tienen repercusión en el gasto de agua de los municipios en los que se localizan ya que se trata de casas rurales y pequeños hoteles con escaso impacto en esta vertiente. El problema vendrá, en todo caso, si se llevan a término actuaciones residenciales en forma de complejos, con miles de alojamientos y, por ende, incrementos del consumo de agua. Por lo demás, los aspectos críticos del abastecimiento de núcleos rurales podrían estar relacionados con las infraestructuras, a la hora de abastecer pedanías rurales o poblamiento diseminado.

A partir de variables de planeamiento, de construcción de vivienda y de dinámicas demográficas, se estima que en el horizonte del año 2025 la demanda superará en este espacio de la MCT los $320 \mathrm{hm} /$ año, frente a los $216 \mathrm{hm}^{3}$ actuales. Este fuerte incremento del consumo de agua potable vendrá motivado por la construcción de nuevas viviendas, destinadas a vivienda principal y segunda residencia. Así, en 2025, a pesar de que la dotación bruta por vivienda descenderá por la mayor eficiencia de la gestión, la Mancomunidad estaría obligada a incrementar las fuentes actuales de suministro en más de $100 \mathrm{hm}$ 3/año. Razones pues para entender que la diversificación de fuentes de abastecimiento es la solución más racional a la hora de mantener un sistema de abastecimiento de agua potable en alta del que depende un volumen de población y una dinámica económica tan significativa.

\section{Bibliografía}

AEAS (2002): Suministro de agua potable y saneamiento en España. VII En cuesta Nacional de Abastecimiento, Saneamiento y Depuración. Asociación Española de Abastecimientos de Agua y Saneamiento. Madrid, 195 pp. 
GIL OLCINA, A. y MORALES GIL, A., (eds.) (1995): Planificación Hidráulica en España. Fundación Caja del Mediterráneo. Alicante. 430 pp.

GIL OLCINA, A. y RICO AMORÓS, A.M. (2007): El problema del agua en la Comunidad Valenciana. Generalitat Valenciana. Fundación Agua y Progreso, Valencia, 221 pp.

MELGAREJO MORENO, J. (dir.) (2009): El trasvase Tajo-Segura: repercusiones económicas, sociales y ambientales en la cuenca del Segura. Edición de la Caja de Ahorros del Mediterráneo, Alicante, $635 \mathrm{pp}$.

MELGAREJO MORENO, J. (ed) (2010): Incidencia del trasvase Tajo-Segura en el sector turístico alicantino. Editorial Fundación COEPA, Alicante.

MORALES GIL, A. (2001): Agua y Territorio en la Región de Murcia. Fundación Centro de Estudios Históricos e Investigaciones Locales. Murcia, 270 pp.

MORALES GIL, A. RICO AMORÓS, A. y OLCINA CANTOS, J. (1996): «Enseñanzas de la sequía en el sureste ibérico» en Marzol, $\mathrm{M}^{\mathrm{a}}$.V., Dorta, P. y Valladares, P. (eds.): Clima y agua. La gestión de un recurso climático. III Reunión Nacional de Climatología, La Laguna, pp. 211-223.

MORALES GIL, A. y VERA REBOLLO, J. F. (1989): La Mancomunidad de los Canales del Taibilla. Instituto Universitario de Geografía de la Universidad de Alicante y Academia Alfonso X El Sabio. Murcia, 132 pp.

OLCINA CANTOS, J. (2002): «Planificación hidrológica y recursos de agua no convencionales en España». En Insuficiencia Hídrica y Plan Hidrológico Nacional, Instituto Universitario de Geografía, Universidad de Alicante, Caja de Ahorros del Mediterráneo, pp. 69-130.

OLCINA CANTOS, J. y RICO AMORÓS, A. (1999): «Recursos de agua «no convencionales» en España. Depuración y desalación», en Gil Olcina, A. y Morales Gil. A. (eds): Los usos del agua en España. Caja de Ahorros del Mediterráneo e Instituto Universitario de Geografía, Alicante, pp. 203-252.

RICO AMORÓS, A.M. (2007) «Tipologías de consumo de agua en abastecimientos urbano-turísticos de la Comunidad Valenciana», en Investigaciones Geográficas, $n^{\circ} 42$, Instituto Universitario de Geografía, Universidad de Alicante, pp. 5-34.

RICO AMORÓS, A. M., OLCINA CANTOS, J. PAÑOS CALLADO, V. BAÑOS CASTIÑEIRA, C. (1998): Depuración, desalación y reutilización de aguas en España. Edit. Oikos-Tau, Vilasar de Mar, 255 pp.

TORREGROSA MARTÍ, M.T. (2009): La gestión del agua en la Marina Baja (Alicante). Edición de les Corts Valencianes, València, 265 pp.

VERA REBOLLO, J.F., OLCINA CANTOS, J. y DIEZ SANTO, D. (2009): Repercusiones del Trasvase Tajo-Segura en el sector turístico de la Región de Murcia, en Melgarejo Moreno, J. (dir): El trasvase Tajo-Segura: repercusiones económicas, sociales y ambientales en la cuenca del Segura. Edición de la Caja de Ahorros del Mediterráneo, Alicante, pp. 465-518.

VERA, J.F. \& IVARS, J.A. (2003): «Measuring Sustainability in a Mass Tourist Destination: Pressures, Perceptions and Policy Responses in Torrevieja, Spain», Journal of Sustainable Tourism, $11,2 \& 3,181-203$.

VERA REBOLLO, J.F. (2005): «El auge de la función residencial en destinos turísticos del litoral mediterráneo: entre el crecimiento y la renovación», en Papers de Turisme, 37-38, pp. 95-114.

VERA REBOLLO, J. F. (2006): «Agua y modelos de desarrollo turístico: la necesidad de nuevos criterios para la gestión de los recursos», en Boletín de la Asociación de Geógrafos Españoles, $\mathrm{n}^{\circ} 42$, pp. 155-178.

VERA, J.F. \& IVARS, J.A. (2009): «Spread of Low-Cost Carriers: Tourism and Regional Policy Effects in Spain», Regional Studies, Routledge, vol. 43, 4, 559-570. 
